\title{
Gestational Trophoblastic Diseases - A Clinicopathological Study
}

\author{
Usha Bhargavi Emani ${ }^{1}$ \\ ${ }^{1}$ Department of Pathology, GSL Medical College, Rajahmundry, Andhra Pradesh, India.
}

\section{ABSTRACT}

\section{BACKGROUND}

The term 'gestational trophoblastic disease', includes lesions, some of which are categorized as true neoplasms, and others that are representative of placentas that are malformed. It refers to various lesions that accompany the premalignant type, some of which are hydatidiform moles of the partial or the whole variety. The malignant type of lesions (GTD / GTN), include the following: choriocarcinoma, epithelioid trophoblastic tumour, placental site trophoblastic tumour, and invasive moles.

\section{METHODS}

A total number of thirty-four cases of GTD during the last two years at a tertiary care hospital was studied, relevant data was collected, and histological features studied.

\section{RESULTS}

$79.41 \%$ of GTDs in the present study were complete mole, $58.82 \%$ of GTDs occurred in nullipara, $52.94 \%$ cases had GTDs seen in the third decade, $14.70 \%$ cases had history of previous GTD, 5.88\% cases had history of previous abortion, $2.94 \%$ cases had a history of previous ectopic pregnancy, and case with choriocarcinoma had the highest HCG levels. In contrast, case with epithelioid trophoblastic tumour had the least HCG levels.

\section{CONCLUSIONS}

In this particular study, it was found that most of the GTDs occurred in nulliparous women in their thirties and their occurrence increased with risk factors like a previous history of GTD, abortions, or ectopic pregnancy.

\section{KEY WORDS}

Choriocarcinoma, Hydatidiform Mole, Gestational Trophoblastic Neoplasms, Gestational Trophoblastic Diseases
Corresponding Author: Dr. Usha Bhargavi Emani, Assistant Professor, Department of Pathology, GSL Medical College, Rajahmundry, Andhra Pradesh, India., E-mail: ushabhargavimani@gmail.com

DOI: $10.14260 / \mathrm{jemds} / 2020 / 636$

How to Cite This Article:

Emani UB. Gestational trophoblastic diseases- a clinicopathological study. J Evolution Med Dent Sci 2020;9(39):29082912, DOI: 10.14260/jemds/2020/636

Submission 05-03-2020,

Peer Review 10-07-2020

Acceptance 17-07-2020,

Published 28-09-2020.

Copyright (c) 2020 JEMDS. This is an open access article distributed under Creative Commons Attribution License [Attribution 4.0 International (CC BY 4.0)] 


\section{BACKGROUND}

The term 'gestational trophoblastic disease', includes lesions, some of which are categorized as true neoplasms, and others that are representative of placentas that are malformed. It refers to various lesions that accompany the premalignant type, some of which are hydatidiform moles of the partial or the whole variety. These growths take form via different subtypes of the placental trophoblast, and each has a terrific pathobiology as a consequence of the proliferative capability of its constituent trophoblast. ${ }^{1}$ A significant symptom of note would be bleeding from the uterus, however haemorrhagic events outside the realm of the uterine system can be the first presentation in an afflicted individual who has spread outside the uterus, namely in the following arenas: CNS, GIT, liver and lungs.2,3 It includes various lesions that accompany the premalignant type, some of which hydatidiform moles of the partial and whole variety. The malignant type of lesions (GTD / GTN), include the following: choriocarcinoma, epithelioid trophoblastic tumour, placental site trophoblastic tumour, and invasive moles. ${ }^{4}$

GTD is a relative rare group of disorders with a very drastically in regards to how they present. Consequently, clinicians face many obstacles when determining the proper course of maintenance and management. The benign presentations are the ones with the most positive prognosis often resulting in a $100 \%$ recovery post-surgical excavation while a segment of $5 \%-8 \%$ need further facilitation via chemotherapy regimens. Ultrasounds, $\beta$-HCG assays and the aforementioned chemotherapy protocols are all quite effective in mitigating the fatal prognosis that was the hallmark of GTD in years prior. An institution of diseases related to standard and abnormal development, which have a common thread linking them, the unusual proliferation of trophoblast tissue, are genetically distinct gestational trophoblastic diseases (GTDs). Individual disorders range remarkably in their appearance (morphology) and scientific significance.5,6 This showcases the importance of undertaking a study to characterize and substantially, contribute to the data on morphological patterns of GTDs in our center. In a study carried out by Hertig, the average incidence for young women in the United States of America (USA) was 1 in 2000 deliveries, ${ }^{7}$ whereas the reported incidence in Southeast Asia was four to five times greater than the USA average. Higher incidences have also been reported from Mexico, the Philippines, India, Taiwan, and Indonesia. 8,9

From a histological perspective, the presentation of complete moles and moles of the partial variety is quite distinctive. Complete moles show as a type of hydatidiform mole which very rarely has or shows an absence of any form of fetal development, shows a hydropic change of almost all the villi, and with extensive trophoblastic hyperplasia. On the contrary, partial mole shows a variable degree of fetal development, showing a characteristic oedematous change of a proportion of the villi, and less focal trophoblastic hyperplasia than seen in a complete mole. From a genetic perspective, complete and partial moles are two very unmistakeable entities. Complete moles for the most part are diploid, and quite often show androgenetic in origin (complete androgenesis), wherein which all the 46 chromosomes will be of paternal origin. In contrast, a significant majority of partial moles are triploid, shaped by dispermic fertilization of a normal ovum (diandric triploidy). Along these lines, both complete and partial moles contain two arrangements of paternal haplotypes (diandric) in the genome. However, unlike a complete mole, which originates from a barren ovum with no maternal genome, a partial mole shows a singular set of chromosomes drawn from the maternal ovum. Thus, early detection of GTN is essential as it allows for a rather good prognosis following proper treatment due to extreme chemo sensitivity showcased by a majority of these lesions.

During the beginning period of regular gestation, the external blastocyst layer (trophectoderm) forms into perivillous trophoblast, later which expeditiously differentiates into extra-villous and villous segments based on location. From a morphological perspective, there are three types of trophoblastic cells: cytotrophoblast, syncytiotrophoblast and intermediate trophoblast. All the types of trophoblasts show powerful positivity with immunohistochemical stains for cytokeratin (including CK 7, 8, 18, and 19), with an exception for cytotrophoblast, are likewise dynamically positive for Placental Lactogen Alkaline Phosphatase (PLAP) and alpha-inhibin. Villous trophoblast are composed of 2 types of cells, cytotrophoblast and syncytiotrophoblast, very minor percentage a third type population of intermediate trophoblast present. Syncytiotrophoblast moreover shows variable energy for beta-human chorionic gonadotropin ( $\beta$-HCG) and human placental lactogen (hPL), contingent upon the gestational age.

\section{Objectives}

- To study the differences in aetiology, clinical behaviour and morphology of various forms of GTD.

- To estimate the mean age of presentation.

- To determine the relative incidence of various forms of GTD.

- To evaluate the relation with the history of previous GTD.

- To study the histological picture of various GTDs.

- To study the correlation with beta-HCG levels.

- To study the correlation with obstetric history.

\section{METHODS}

After obtaining approval from the ethical committee, thirtyfour cases of GTD seen during last two years at a tertiary hospital were studied. Relevant data was collected, and histological features were studied. Relevant information about the patient like age, obstetric history, past history of GTD, ectopic pregnancy, abortions were noted down from respective case sheets and old reports available with patients, histopathology reports collected including the gross finding and microscopic findings and immunohistochemistry. They were tabulated and analysed. This is a cross sectional study.

\section{Statistical Analysis}

Data was analysed using Microsoft Excel. Data is depicted as proportions. 


\section{RESULTS}

\begin{tabular}{|ccc|}
\hline Age & No. of Cases & Percentage \\
\hline Up to Second Decade & 15 & 44.11 \\
Third Decade & 18 & 52.94 \\
Fourth Decade & 01 & 2.94 \\
& Table I. Age Distribution & \\
\hline
\end{tabular}

\begin{tabular}{|c|c|c|}
\hline Type of GTD & No. of Cases & Percentage \\
\hline Partial Mole & 04 & 11.76 \\
\hline Complete Mole & 27 & 79.41 \\
\hline Invasive Mole & 01 & 2.94 \\
\hline Choriocarcinoma & 01 & 2.94 \\
\hline $\begin{array}{c}\text { Epithelioid Trophoblastic } \\
\text { Tumour }\end{array}$ & 01 & 2.94 \\
\hline $\begin{array}{l}\text { Placental Site Trophoblastic } \\
\text { Tumour }\end{array}$ & 00 & 00 \\
\hline Exaggerated Placental Site & 00 & 00 \\
\hline Placental Site Nodule & 00 & 00 \\
\hline
\end{tabular}

\begin{tabular}{|ccc|}
\hline History & No of Cases & Percentage \\
\hline Previous GTD & 06 & 17.64 \\
Previous Abortion & 04 & 11.76 \\
Nulliparous & 23 & 67.64 \\
Previous Ectopic Pregnancy & 01 & 2.94 \\
\hline \multicolumn{2}{|c|}{ Table III. Obstetric History } \\
\hline
\end{tabular}

$79.41 \%$ of GTDs in the present study were complete mole, $58.82 \%$ of GTDs occurred in Nullipara, $52.94 \%$ cases had GTDs seen in third decade, $14.70 \%$ cases had history of previous GTD, 5.88\% cases had history of previous abortion, 2.94\% cases had history of previous ectopic pregnancy, case with choriocarcinoma had the highest HCG levels whereas case with epithelioid trophoblastic tumour had the least HCG levels.

\section{DISCUSSION}

GTD incorporates a range of tumours and tumour like situations characterized by multiplication of pregnancy associated trophoblastic tissue which retain the potential to develop into a malignancy. ${ }^{10}$

GTD represents hereditarily unusual, non-feasible gestation associated with a trophoblast proliferation which could exhibit neoplastic potential. A significantly high incidence rate can be found in women from Asia, Latin America and the Middle East. ${ }^{11}$

\section{Complete Mole}

This pathology is more evident in a complete mole, because of the absence of attenuating influence of a maternal genome, and also risk of neoplastic transformation is greater. Complete molar pregnancy comprises almost of $75 \%$ among all GTD, is commonest and has bimodal age incidence of the reproductive period, when there is deviation in normal gametogenesis and fertilization are most likely. Almost all cases arise followed by fertilization of an empty ovum, absence of maternal chromosomes by a normal single sperm cell, which then duplicates its allele. Rarely, few of these moles may also be tetraploid (4n). The residual cases are usually due to dispermic fertilization of an "empty" ovum. A total of 27 cases of complete mole were studied.
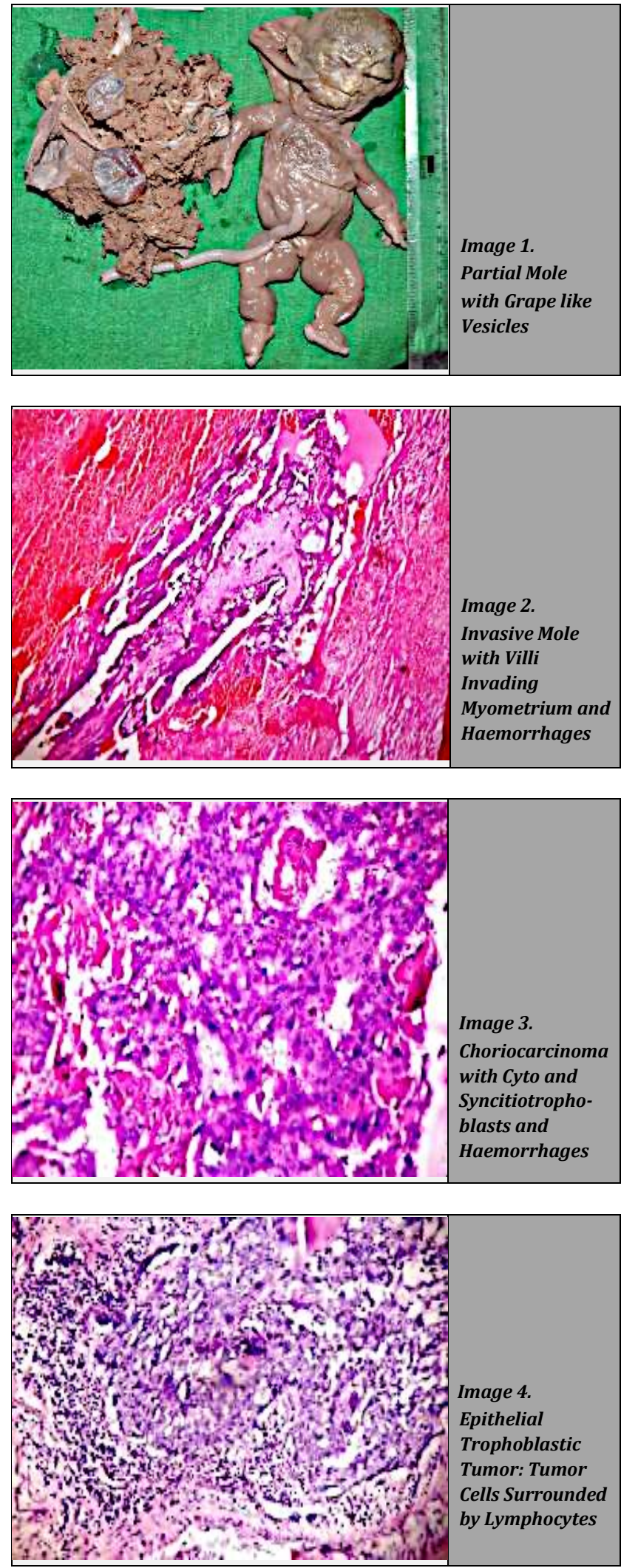

\section{Partial Mole}

Partial moles that include a fetus are a somewhat rare variation of a molar pregnancy that is a result of dispermic fertilization of a normal oocyte with haploid set of chromosomes and end result is a triploid set of chromosomes. It can account for $0.005 \%$ to $0.01 \%$ of all pregnancies. A jump in the incidence rate could be explained by the extensive utilization of artificial reproductive techniques. ${ }^{12}$ There are 3 
variants of molar pregnancy including a standard live fetus: the most frequently occurring case is a twin pregnancy with the presentation of one normal fetus and a normal placenta while another complete mole; the second variant is a twin pregnancy with regular fetus and placenta and another being a partial mole the third and most uncommon occurrence that, to date, was reported only 19 times in the literature: a singleton normal fetus with partial molar placenta, which is similar to our present case. ${ }^{13}$

\section{Invasive Mole}

Invasive moles are predominant in a vast majority of cases regarding localized gestational trophoblastic diseases. They can emerge from any type of pregnancy event but in most cases it is discovered after molar pregnancy. Overall complete recovery and cure rate in low risk group patients is close to $100 \%$ and close to $90 \%$ for patients in the high risk group. In a minute number of cases, molar tissue can traverse all the thickness of myometrium and can cause perforation and presents as acute abdomen and invasive mole very rarely it can metastasize. The best treatment methodology is chemotherapy according to the stage and score with single or various pharmacological operators and in patients who have finished establishing a family, hysterectomy should be feasible. Invasive mole is complete or partial penetration of the molar tissue (complete or partial mole) into myometrium or uterine mesenchyme, chorionic villi and proliferating trophoblastic cells invade myometrium, this is how it can be distinguished from choriocarcinoma. For that reasons histopathologists will be mentioning the existence/ absence of villi in the growth. Locally invasive gestational trophoblastic neoplasia can be seen to develop in $15 \%$ of patients and metastatic form in $4 \%$ of patients followed by complete evacuation of complete mole and less frequently after partial mole. ${ }^{14}$

Metastasis can occur from direct extension of another pelvic neoplasm or by hematogenous or lymphatic spread or by transcoelomic dissemination. High HCG level, large uterine enlargement, theca lutein cyst size of more than $6 \mathrm{~cm}$ are cases that are most liable to develop into post molar tumours which are considered a high-risk presentation. However, a common and characteristic symptom of invasive mole is bleeding per vaginum post evacuation of molar pregnancy, and subinvolution of uterus and persistent theca lutein cyst. Clinicians observe and monitor any variations of the $\beta$-HCG titer, as it is rather helpful in the diagnosis of a mole of the invasive variety. Despite the fact that the gold standard of invasive mole diagnosis has always been a thorough histopathological examination, in the modern clinical setting, ultrasonography paired with monitoring of $\beta$-HCG levels has also proven effective in the process of properly identifying presentations of invasive moles.

Invasive moles are almost completely curable with chemotherapy while a hysterectomy minimizes the need for repeated courses of chemotherapy with methotrexate. However, chemotherapy does have its uses in order to mitigate complications in cases involving excess haemorrhage or prolonged infection. In majority of cases, Invasive mole is diagnosed rather suspected clinically than pathologically based on persistent hCG levels elevation after $r$ evacuation of molar pregnancy and is most commonly treated with chemotherapy without a histopathologic diagnosis in most of cases. ${ }^{15}$

\section{Choriocarcinoma}

Gestational choriocarcinoma is the most common form of malignant GTD and shows differentiation towards villous trophoblast which are made up of cytotrophoblasts \& syncytiotrophoblasts. Choriocarcinoma generally presents with bleeding per vaginum but in many cases metastatic disease may be the first manifestation, that too followed by a non-molar gestation. Grossly this tumour characteristically has a friable haemorrhagic appearance, with varied number of nodules. Extensive necrosis and/or haemorrhage are seen because of absence of an inherent blood supply to the neoplasm. Microscopically, the tumour characteristically has a biphasic pattern comprising of both mononuclear cyto- and multinucleated syncytiotrophoblast present and in most of the cases tumour cells, are seen only in peripheral location. Post chemotherapy may alter the microscopic picture showing only bizarre mononuclear cells. If left untreated, this neoplasm can be an extremely aggressive tumour, showing vascular metastases most often within the vagina, pelvis, liver, lung and brain. A small neoplasm can still have widespread metastatic disease. On the contrary gestational choriocarcinoma is rather chemo responsive and generally treated successfully with chemotherapy. Tumour resection however can be done in case of resistant disease.

\section{Epithelioid Trophoblastic Tumour}

Epithelioid trophoblastic tumour is a very uncommon variation of threatening GTD, that showcases some separation towards chorionic-type extra villous trophoblast/halfway trophoblast and is as of late considered as a variation of PSTT. It might speak to the harmful partner of placental site trophoblastic knob (PSN) and as PSN, a typical PSN and ETT have been depicted close to one another. Patients typically present with draining PV and insignificant rise of serum $\beta$ HCG. This tumour is commonly very much encompassed and shows little mononuclear cells in foundation of hyaline stroma admixed with zones of necrosis and a trademark nodular growth pattern.

Study by Taboo ZA had peak incidence of GTD was among 20 - 25 years age group. ${ }^{16}$ Another study in India conducted by Kumar N et al., had $66 \%$ of GTD patients in the age group of 20 25 years. ${ }^{17}$ Another reported obstetric risk factor for both complete and partial moles is a history of spontaneous abortion, giving females a 2- to 3-fold increased risk of a molar pregnancy compared to women without a history of miscarriage. ${ }^{18}$

\section{CONCLUSIONS}

According to Le-Mingshih, Michael T. Mazur and Robert J. Kurman, the most common form of GTD was partial mole. Most commonly GTDs are encountered in less than 20 years and more than 40 years age groups. Most of the GTDs occurred in nulliparous women in their third decade of life and its occurrence increased with risk factors like previous history of 
GTD, abortions, ectopic pregnancy. Follow-up after evacuation of a hydatidiform mole is always essential to look for trophoblastic sequelae, to see whether it will be invasive mole or choriocarcinoma which can develop in approximately 15 $20 \%$ with complete mole and $1-5 \%$ with partial mole. ${ }^{19-23}$

Financial or Other Competing Interests: None.

\section{REFERENCES}

[1] Hui P, Baergen $R$, Cheung $A$, et al. Gestatinoal trophoblastic disease. In: Kurman R, Carcangiu ML, Herrington S, et al, eds. WHO classification of tumours of female reproductive organs. $4^{\text {th }}$ edn. Lyon, France: International Agency for Research on Cancer 2014.

[2] Horn LC, Bilek K. Clinicopathologic analysis of gestational trophoblastic disease--report of 158 cases. Gen Diagn Pathol 1997;143(2-3):173-8.

[3] Lurain JR, Casanova LA, Miller DS, et al. Prognostic factors in gestational trophoblastic tumours: a proposed new scoring system based on multivariate analysis. Am J Obstet Gynecol 1991;164(2):611-6.

[4] Seckl MJ, Sebire NJ, Berkowitz RS. Gestational trophoblastic disease. Lancet 2010;376(9742):717-29.

[5] Rosai J. Pregnancy, trophoblastic disease and placenta. In: Rosai and Ackerman's surgical pathology. $10^{\text {th }}$ edn. St. Louis, Washington: Elsevier 2011:1636-45.

[6] Shih IM. Gestational trophoblastic neoplasia-pathogenesis and potential therapeutic targets. Lancet Oncol 2007;8(7):642-50.

[7] Hertig AT. Hydatidiform mole and chorionepithelioma. In: Meigs JV, Sturgis SH, eds. Progress in gynaecology. New York: Grune and Stratton 1950:372-94.

[8] Park WW. Choriocarcinoma: a study of its pathology. London: William Heinemann Medical Books 1971: p. 58.

[9] Berkowitz RS, Goldstein DP. Chorionic tumours. N Engl J Med 1996;335(23):1740-8.

[10] Lurain JR. Gestational trophoblastic disease I: epidemiology, pathology, clinical presentation and diagnosis of gestational trophoblastic disease, and management of hydatidiform mole. Am J Obstet and Gynecol 2010;203(6):531-9.
[11] Crum CP, Lee Y, Genest DR. Tumours of the placenta and gestational trophoblastic disease. In: Fletcher CDM, ed. Diagnostic histopathology of tumours. $3^{\text {rd }}$ edn. Churchill Livingstone 2007:674-80.

[12] Malhotra N, Deka D, Takkar D, et al. Hydatidiform mole with coexisting live foetus in dichorionic twin gestation. Eur J Obstet Gynecol Reprod Biol 2001;94(2):301-3.

[13] Kawasaki K, Kondoh E, Minamiguchi S, et al. Live-born diploid fetus complicated with partial molar pregnancy presenting with pre-eclampsia, maternal anemia, and seemingly huge placenta: a rare case of confined placental mosaicism and literature review. J Obstet Gynaecol Res 2016;42(8):911-7.

[14] Seckl MJ, Fisher RA, Salerno G, et al. Choriocarcinoma and partial hydatidiform moles. Lancet 2000;356(9223):36-9.

[15] Lurain JR, Brewer JI. Invasive mole. Semin Oncol 1982;9(2):174-80.

[16] Taboo ZAA. A prospective study of gestational trophoblastic disease in Al-Mosul City. The Iraqi Postgraduate Medical Journal 2013;12(2):268-76.

[17] Kumar N, Saxena YK, Rathi AK, et al. Host and risk factors for gestational trophoblastic disease: a hospital based analysis from India. Med Sci Monit 2003;9(10):CR442-7.

[18] Parazzini F, Mangili G, La Vecchia C, et al. Risk factors for gestational trophoblastic disease: a separate analysis of complete and partial hydatidiform moles. Obstet Gynecol 1991;78(6):1039-45.

[19] Berkowitz RS, Goldstein DS. Clinical practice. Molar pregnancy. N Engl J Med 2009;360(16):1639-45.

[20] Lurain JR, Brewer JI, Torok EE, et al. Natural history of hydatidiform mole after primary evacuation. Am J Obstet Gynecol 1983;145(5):591-5.

[21] Feltmate CM, Batorfi J, Fulop V, et al. Human chorionic gonadotropin follow-up in patients with molar pregnancy: a time for reevaluation. Obstet Gynecol 2003;101(4):732-6.

[22] Feltmate CM, Growdon WB, Wolfberg AJ, et al. Clinical characteristics of persistent gestational trophoblastic neoplasia after partial hydatidiform molar pregnancy. J Reprod Med 2006;51(11):902-6.

[23] Goto S, Yamada A, Ishizuka T, et al. Development of postmolar trophoblastic disease after partial molar pregnancy. Gynecol Oncol 1993;48(2):165-70. 